\title{
Metodologias ativas na formação do engenheiro do século XXI: desafios e reflexões
}

\author{
Active methodologies in the formation of the $X X \mid$ century engineer: \\ challenges and reflections
}

Metodologías activas en la formación del ingeniero del siglo XXI: desafíos y reflexiones

Felipe Korbus Sutili'

https://orcid.org/0000-0002-6080-927X

lara Alessandra Donati Raineri ${ }^{2}$

https://orcid.org/0000-0002-4|32-5253

Resumo: Em uma sociedade em constante transformação e avanços tecnológicos rápidos, a principal característica de um profissional competitivo é a capacidade de criar e aplicar ciência e tecnologia na geração de bens e serviços. Para isso, são necessários bons questionamentos, dúvidas que o destacarão como profissional e farão diferença à comunidade como um todo. Deste modo considerando a necessidade de progresso e as mudanças contemporâneas de um mundo cada vez mais globalizado e hiperconectado, objetiva-se analisar o atual cenário de aprendizagem e as formas de ensino usadas como subsídio ao desenvolvimento do estudante de engenharia. Para tanto, parte-se da análise de alguns fatores históricos e filosóficos que levaram o discente a um enrijecimento do seu poder de questionamento, para proceder-se à análise de metodologias ativas de ensino, como Aprendizado Baseado em Problemas (ABP), Metodologia de Problematização (MP) e Aprendizagem Baseada em Equipes (ABE). A utilização dessas ferramentas permite o enquadramento do aluno como gestor do próprio aprendizado e leva a concluir pela necessidade da busca de métodos alternativos para o rompimento da passividade do corpo discente.

Palavras-chave: Engenheiros. Competitividade. Metodologias ativas.

Abstract: In a society in constant transformation and rapid technological advances, the main characteristic of a competitive professional is the ability to create and apply science and technology in the generation of belongings and services. For this, good questions are cool, doubts that will highlight you as a professional and make a difference to the community as a whole. Thus, considering the need for progress and as contemporary changes in an increasingly globalized and hyperconnected world, the objective is to analyze the current learning scenario

${ }^{1}$ Doutor em Ciências. Professor da Universidade Estadual Paulista “Júlio de Mesquita Filho” - UNESP. E-mail: felipe.sutili@unesp.br

${ }^{2}$ Especialista em Língua de Sinais e em Deficiência Intelectual. Professora da União de Ensino Superior de Piraju/ Faculdade Corporativa CESPI- FACESPI. E-mail: iara1986I@hotmail.com 
and the forms of teaching used as a subsidy for the development of the engineering student. To do so, it starts from the analysis of some historical and philosophical factors that led the student to a stiffening of his questioning power, to proceed with the analysis of active teaching methodologies, such as Problem Based Learning (ABL), Questioning Methodology (MP) and Team-Based Learning (ABE). The use of these tools allows the framing of the student as a manager of his own learning and leads to the granting of the need to search for alternative methods to break the passivity of the discente group.

Keywords: Engineers. Competitiveness. Active methodologies.

Resumen: En una sociedad en constante transformación y rápidos avances tecnológicos, la principal característica de un profesional competitivo es la capacidad de crear y aplicar ciencia y tecnología en la generación de bienes y servicios. Para ello se necesitan buenas preguntas, dudas que te destaquen como profesional y marquen la diferencia para la comunidad en su conjunto. Así, considerando la necesidad de progreso y cambios contemporáneos en un mundo cada vez más globalizado e hiperconectado, el objetivo es analizar el escenario de aprendizaje actual y los métodos de enseñanza utilizados como subvención para el desarrollo del estudiante de ingeniería. Para ello, se parte del análisis de algunos factores históricos y filosóficos que llevaron al alumno a un fortalecimiento de su poder cuestionador, para proceder al análisis de metodologías docentes activas, tales como Aprendizaje Basado en Problemas (ABP), Metodología de la Enseñanza. (PM) y Aprendizaje basado en equipos $(A B E)$. El uso de estas herramientas permite enmarcar al alumno como gestor de su propio aprendizaje y lleva a la conclusión de que es necesario buscar métodos alternativos para romper con la pasividad del alumnado.

Palabras-clave: Ingenieros. Competitividade. Metodologías activas.

\section{Paradigma atual docente-discente}

A ênfase da configuração de aprendizagem do século $X X I$ não se restringe apenas ao poder cognitivo e sim se espalha pelo sinergismo dos domínios salientes: cognitivo, afetivo e psicomotor (YANI e ADIANSYAH, 20I7). Apesar de passados quase um quinto do presente século, ainda não se entende e nem se domina os processos, tampouco as ferramentas de preparação do engenheiro do futuro.

O processo educacional epistemológico de Piaget (TSOU, 2006), bem como o de pedagogos behavioristas (AKERA, 2017), baseado no "método bancário" onde somente o professor é o detentor do conhecimento e o deposita no aluno, se tornou arcaico, obsoleto. Muitos estudantes, até aqueles com boas notas, passam pela escola pautada nesse processo e chegam à universidade sem saber estudar, com uma percepção de interdisciplinaridade e interdependência defasada, sem conseguir relacionar os conteúdos e encontrar aplicações em sua vida.

Outro fator influente no processo educacional dissonante à educação é a segregação dos conhecimentos, que com o cunho organizacional de otimização, baseado em preceitos tecnicistas na busca da eficiência, fez com que algumas áreas do conhecimento passassem a ser separadas de outras que são importantes no processo criativo, no concatenar de ideias e vivências, bem como no estímulo de pensamentos. É o caso da filosofia, que era estudada por muitos "cientistas" gregos e hoje essa fusão dicotômica entre "corpo e a mente" faz falta aos alunos em áreas como a de exatas. Reconhecese que a tecnologia é resultante da ciência, mas esqueceu-se que a ciência vem da filosofia (CHIESA, 2006). 
De modo semelhante, com a objetivação do trabalho pedagógico, o trabalho fabril da segunda era Industrial (séc. XIX) teve a necessidade de formar trabalhadores obedientes, uma classe de pessoas dedicadas todos os dias a fazer os mesmos movimentos. Naquela época, a maquinização em massa do ser humano o deixou cada vez mais distante dos momentos de indagação e mais próximo de um sistema alienante e que até os anos 80 refletiu na educação dos nossos alunos através da corrente filosófico-psicológica do behaviorismo (CHIESA, 2006).

Hoje, o aluno adota uma posição ainda mais passiva de aprendizado, diante de todas as facilidades propiciadas pela tecnologia, como para escutar música, assistir filmes, se deslocar, realizar transações bancárias, se comunicar, se relacionar com outras pessoas, obter informação, entre outras atividades. Essa passividade resulta em um discente quiescente, que não desenvolve questionamentos pertinentes ao seu meio, com dificuldades na quebra do seu cárcere intelectual (DEMO, 2000).

Vê-se a minimização do uso da rede social Facebook, por exemplo, e crescimento de usuários em outras plataformas, como o Instagram. Isso é uma das evidências da passivação da sociedade diante da informação, ou seja, da preferência pela obtenção de informes visuais, com pouco conteúdo, gerando um movimento instintivo de cunho emocional propiciado pela contemplação do objeto, contentando apenas os olhos e consequentemente minimizando a essência. Assim, com esse excesso de informes propiciadas pela tecnologia, há grande dificuldade na atração da atenção dos estudantes pelos conteúdos ministrados em cursos superiores. Tudo isso é exacerbado ainda mais pela falta de estímulo do docente no processo de aprendizado através da elaboração de atividades atrativas ao aluno (COHEN et al., 2017)

Atrelado a esse excesso de informação, desse pensamento acelerado, surgem as síndromes da era digital como a FOMO (Fear of Missing Out) que é o medo de estar "perdendo" algo na internet (PRZYBYLSKI et al., 20I3), nas redes sociais, que maximizam o dano no processo de aprendizagem, fazendo com que o aluno perca ainda mais atenção ao que é aprendido na universidade e não dando a devida importância ao professor.

O modelo de educação centrado no professor exacerba-se em um curso de caráter tecnicista, em que as áreas de conhecimento são muito fixas como nas engenharias. Dessa forma, quem mais aprende são os próprios professores, que se preparam e se atualizam cada vez mais em seu campo, retendo para si as condições que promovem a aprendizagem.

Entidades como a Confederação Nacional das Indústrias (CNI) e a Mobilização Empresarial pela Inovação (MEI), preocupadas com a qualidade de ensino das engenharias no Brasil, lançaram em 2018 um documento com diretrizes e recomendações para o fortalecimento e modernização do ensino de engenharia no Brasil (CNI, 2018). O mercado atual, altamente globalizado e transformado, requer um engenheiro que tenha uma formação baseada em preceitos como: empreendedorismo, trabalho 
em equipes multidisciplinares, desenvolvimento e administração de projetos, liderança e capacidade de aprendizado independente. Para isso, precisa-se não apenas de um engenheiro solucionador de problemas e sim um profissional que resolva essas questões e gere outras ideias problematizadoras com o intuito de melhorar os processos, a indústria, enfim, o seu ambiente de uma maneira geral. Ou seja, é preciso formar engenheiros não só de ação, mas também de ideias. Assim, trabalhar com a proatividade do aluno é um caminho viável na busca de um profissional adaptado e dinâmico, que compreenda as diferenças entre o know how e o know why (CARVALHO et al., 2017).

$O$ engenheiro de hoje necessita de competências que extrapolem a multidisciplinaridade. Além de lidar com gestores e profissionais de diferentes áreas, precisa reconhecer e encontrar elos entre os diferentes ramos. Essa interdisciplinaridade auxilia na concatenação de ideias e até pode aumentar a atuação do seu campo profissional. O profissional moderno tem de estar aberto a interdisciplinaridade, auxiliando na evolução da ciência em todas as áreas, como na saúde, através do controle, cura e/ou prevenção de doenças, melhorando a vida da sociedade. Um exemplo disso é o de engenheiros de grandes montadoras, que mesmo sem conhecimento em medicina, trabalham em conjunto com médicos no sequenciamento proteico através de softwares na simulação de drogas para o tratamento de diferentes enfermidades (BARH et al., 2016), sendo os educadores/professores que devem estimular essa conexão e indagação nos discentes.

Para haver a geração de questionamentos pertinentes, o aluno precisa adotar uma postura como a de um cientista, onde ele se envolve com um determinado assunto e com os diversos pontos de reflexão sobre o tema (VIANNA; CARVALHO, 2000). Contudo, para isso ocorrer deve-se induzir a democratização, a inclusão em sala, dando a possibilidade ao aluno de questionar, argumentar, debater sobre o assunto frente ao seu conhecimento pregresso, trocando conhecimento de uma maneira horizontal e não só vertical com o professor. Sim, pois se vive em uma era em que o discente possui uma bagagem que pode ser relacionada com o conteúdo em pauta, novo, não sendo mais considerado um livro sem história, em branco.

No entanto, para que isso ocorra, é necessário que o docente tenha empatia intelectual, não só com relação ao conteúdo que está ministrando, mas também ao discente, reconhecendo os seus saberes, a sua biografia. Além disso, a empatia é fundamental para a fluidez desse estímulo, desse acolhimento, pois pressupõe o deslocamento do "eu" em direção ao "outro". Porém, não através do paternalismo ou da permissividade que, de certa forma, se torna pouco comprometida, e sim pela propagação e exercício de um amplo respeito à existência do aluno, sem detrimento do conhecimento.

Assim sendo, mantem-se o atual retrato do modelo educacional, com o arquétipo de metodologias rotineiras e cansativas, aliado a falta de participação justificada pelos alunos, continua-se em um ciclo vicioso que tende ao individualismo, onde os profissionais que se destacam são apenas os 
que encontram sozinhos as ferramentas para a superação dos paradigmas intelectuais. Esse ciclo vicioso acarreta em profissionais que não atendem a expectativa do mercado diminuindo a absorção desses. Modificar esse cenário é primordial para o bom desenvolvimento das indústrias brasileiras e consequente geração de emprego e melhoria da economia.

Como transpor o atual paradigma de aprendizagem e formar engenheiros e cidadãos qualificados para o século $X X I$, gerando um novo movimento de significação e ressignificação dos saberes e práticas? Será que apenas as metodologias educacionais usadas hoje serão suficientes para o desenvolvimento de cidadãos qualificados para um mundo moderno? Levando em consideração os aspectos abordados, o objetivo do presente artigo é conjecturar sobre esses e outros questionamentos servindo de ponto de partida a demais elucubrações concernentes a uma educação pós-modernista e pós-pandêmica a luz de metodologias ativas.

\section{Metodologias alternativas}

As metodologias alternativas ou metodologias educacionais estimuladoras, também chamadas de metodologias ativas, são consideradas processos educativos que envolvem atitudes, convicções e interações. São desenvolvidas para ativarem a "inquietação" dos alunos em determinado assunto, para que esses possam fortalecer não só a independência, mas também a autonomia, comprometendo-se com seu aprendizado. Essa "inquietação", que também pode ser chamada de energia, já foi motivo para reflexões dos mais variados pensadores em suas respectivas épocas e designada de diferentes formas. Por exemplo, Baruch Espinosa (séc. XVII) chamava de potência de agir (PAULA, 2009), Sigmund Freud (séc. XIX) a chamou de libido (COSTA et al., 20II), Arthur Schopenhauer (séc. XIX) de vontade (SOUSA, SÁ RAMALHO, 2019), e Friedrich Nietzsche (séc. XIX) de vontade de potência (NIETZCHE, 20II). Atualmente, as chamadas metodologias ativas remontam de antigas ideias, com contribuições filosóficas diretas e indiretas de alguns desses pensadores, que se coadunaram no final do século XIX, de se trabalhar com projetos com uso dos recursos pedagógicos que estimulem técnicas de ensino e/ou aprendizagem crítico-reflexivas. Kant (séc. XIX), por exemplo, no lluminismo já usava a nomenclatura de 'aprendizagem ativa', onde incutia esse tipo de reflexão (SANTOS; FERRARI, 2017).

As metodologias ativas têm por propósito orientar o estudante a desvendar um fenômeno e a assimilar conceitos autonomamente e, posteriormente, dirigi-lo a concatenar suas pesquisas com seu conhecimento pregresso do mundo ao seu redor. Os conceitos das metodologias ativas giram em torno de preceitos de engajamento, autogestão do aprendizado, participação, autonomia e reflexão. Contudo, para que isso ocorra, é necessário um intermediador que seja responsável pela organização e orientação deste sistema, por induzir o brotamento de pensamentos, fugindo do estereótipo de transferidor de conteúdo (CARVALHO et al., 2017). 
A forma de aprender, com o passar do tempo, sofre mudanças. Os alunos foram criados de diferentes maneiras que induziram as formas diversas de aprendizado. Assim, esperar que em uma sala de cerca de cem pessoas todos ganhem proficiência de maneira semelhante não é uma expectativa real. A corrente da Programação Neurolinguística afirma que "reinterpretamos" o mundo que nos cerca através de nossa personalidade e pela predominância de alguns sentidos sobre outros (TOSEY; MATHISON, 2003). Existem pessoas que são auditivas, que se conectam melhor com o mundo escutando, outras são visuais, e um terceiro grupo, os cenestésicos, que se adaptam melhor com contato físico, ou seja, são mais efetivos através de uma comunicação com estímulos táteis. Dependendo de quão aguçado é esse sentido, a absorção de informações pode ser maior por essa via. $\mathrm{Na}$ educação, alguns autores, como Felder (1996), vão ao encontro da Neurolinguística e classificam o aprendizado dos alunos por estilos diversos, como visuais ou verbais, indutivos ou dedutivos, ativos ou reflexivos. Há ainda misturas auxiliares de arranjos essenciais destas classificações iniciais. Em outras palavras, cada indivíduo tem uma maneira singular de assimilar conhecimento e informação, maximizando assim o seu rendimento de aprendizagem.

Já o psiquiatra americano William Glasser (1960 apud SILVA; MUZARDO, 2018) subdividiu e quantificou a retenção de conteúdo de acordo com as formas de aquisição, através de uma pirâmide de aprendizagem. Glasser infere que a taxa de retenção dos conteúdos varia com a forma com que ele é apresentado à pessoa. Ele alega que quando o assunto é exposto de maneira tradicional, ou seja, através de uma palestra, de uma exposição oral, a retenção de conteúdo é de mais ou menos $5 \%$. Quando se dá através de leitura, a retenção é de $10 \%$, já para informes audiovisuais de $20 \%$, demonstração $30 \%$, discussão em grupo 50\%, já através da realização de prática chega a $75 \%$. Por fim, a retenção é de $90 \%$ através de outras formas de ensino, que abrem precedente para novas metodologias de aprendizado.

Ainda que alguns autores afirmem que não existe indicação de pesquisas científicas que possam embasar a correlação da pirâmide com as tipologias de aprendizagem e seus respectivos números, essas generalizações ainda são bastante sólidas e utilizadas para defender as metodologias ativas de aprendizagem, pois dão suporte a modelos de retenção e contribuem para a inserção do aluno no centro do processo ensino-aprendizado (SILVA; MUZARDO, 20I8).

Confúcio, pensador e filósofo chinês, em sua máxima formulada há dois mil e quinhentos anos vai ao encontro dos preceitos da pirâmide de aprendizagem, favorecendo o emprego de formas de aprendizagem mais participativas e envolventes em sala de aula. Ele disse "o que eu ouço, eu esqueço; o que eu vejo, eu lembro; o que eu faço, eu compreendo" (HORTON, 200I). Ou seja, você realmente compreende, prende a informação para si, quando transmite o que aprendeu ao outro. A matéria e as 
competências têm de ser debatidas e exercitadas até o que o aluno seja capaz de dominar o assunto e falar a respeito com seus pares.

A discussão, seja ela introspectiva ou com o outro, pode nos levar a construção de um conhecimento coeso, que seja útil na transformação da informação. Através de indagações coerentes e bem orientadas é possível conduzir o aluno a uma autorreflexão e conclusão. Era assim que Sócrates ( $V$ a. c.) instruía seus discípulos, instigava habilidades de pensamento crítico gerando a autorreflexão e o autoconhecimento (CATALANI; VELASCO, 20I4). Tudo para que os seus seguidores através de questionamentos se sentissem responsáveis por não os haverem sanado e tivessem a capacidade de aprender o que necessitassem.

Assim, as metodologias ativas são estimuladoras da reflexão e se baseiam na "maiêutica" socrática, suscitando a dúvida, o que achamos ser as verdades concretas sobre vários pensamentos, para que saiamos do nosso labirinto intelectual. Mayer (2012) salienta que o Método Caso, um tipo de metodologia ativa inicialmente adotado pela Harvard Business School a partir de 1908, possui semelhanças com a estratégia Socrática que se propõe a demostrar que a sua máxima é coerente com a natureza humana, ou seja, "sei que nada sei". Em outras palavras, tem-se apenas a impressão através da conviç̧ão de que se sabe algo, mas jamais a certeza.

A busca da verdade concreta em qualquer área do conhecimento deve ser constante para que ocorra a quebra dos dogmas e ceticismos que travam a evolução dos saberes e aferram intelectualmente o ser. Um dos maiores opositores da educação é o engano de que sabemos quando na verdade não sabemos. Em um mundo hiperconectado nos iludimos com a informação, achando que temos conhecimento, e, assim, perdemos o senso crítico que é forjado através de um entendimento sistematizado. Para dirimir isso, devemos abandonar os preconceitos e falsidades, admitindo a nossa ignorância em diversos momentos. Instaurar a compreensão de que o próprio saber é insatisfatório para o entendimento da totalidade dos fenômenos. Isto se torna possível através da humildade que leva o homem ao reconhecimento de sua finitude, dos limites do seu conhecimento, através de uma auto avaliação incessante, ou seja, tornarmo-nos coletores e questionadores perenes de "verdades absolutas" (CORNILLE, 2007).

Algumas metodologias se tornam mais oportunas ao ensino superior por desencadearem um fluxo de ideias através de questionamentos em busca de soluções em temas específicos. A área da Engenharia é propícia para aplicação dessas perturbações intelectuais por difundir e consolidar conceitos empíricos e instintivos, que, além destes focos, levantam a probabilidade do uso dos conhecimentos adquiridos durante a graduação. Além disso, tais metodologias permitem que a prática pedagógica extrapole os limites do treinamento tão somente técnico e habitual, possibilitando a formação do sujeito como um ser ético, analítico e reflexivo. 
As estratégias de aprendizagem, segundo Abreu e Masetto (1990), são agrupadas em categorias de objetivos, que podem ser atreladas a várias metodologias ativas. A categoria chamada de Primeiro Encontro compreende o aquecimento, desbloqueio, usados para apresentação de membros, para a estimulação da classe, ou para o desbloqueio em situações em que a produção fica paralisada por conta de fatores emocionais adjacentes. A categoria de Situações Simuladas traz situações que reproduzem ou se assemelham a situação real equivalente. A categoria de Confronto com situações reais, por sua vez, coloca os alunos em contato através de um encaminhamento real. Já a categoria de Pequenos Grupos estimula o trabalho cooperativo dos alunos. A Categoria Especialista e/ou Preparação Prévia exige a presença de especialista e/ou preparação dos alunos. A categoria da Pesquisa e Projetos motiva a independência e autonomia dos alunos. E, por fim, a categoria Base em Leitura e Escrita complementa as demais categorias.

Dentre essas categorias, as características daquelas que trazem uma proposta problematizadora, o trabalho em grupo e o aprender fazendo podem ser destacadas para a aplicação das metodologias ativas em engenharia.

Assim, diante das várias metodologias existentes e utilizadas no ensino de engenharia, destacaremos: o Aprendizado Baseado em Problemas (ABP) ou Problem-base learning (PBL), a Metodologia de Problematização (MP) ou Inquiry-Based Learning (IBL) e a Aprendizagem Baseada em Equipes (ABE) ou Team-Based Learning (TBL), refletindo sobre a importância dessas metodologias na formação do engenheiro.

\section{Aprendizado Baseado em Problemas (ABP) ou Problem-Base Learning (PBL)}

Segundo Dewey "a educação devia ser concebida como uma reconstrução contínua da experiência” (1897, p. 78). Ele afirma que o estopim da aprendizagem é gerado por problemas ou situações que os intencionam através de perturbações intelectuais. Nada melhor que a resolução de problemas para gerar essas inquietações encorajando o aluno a um aprendizado individual e significativo. Isso permite que o aluno se torne o "autor" de seu próprio conhecimento, desempenhando um trabalho funcional constante e coerente com um cenário em que prossiga com a instrução e a autoaprendizagem (RIBEIRO; MIZUKAMI, 2004; SHMIDT, 1983), algo cada vez mais notório em um contexto integrado e em constante transformação na engenharia.

A ABP planeja capacitar os alunos a seguir suas habilidades básicas de raciocínio com uma abordagem científica. Propõe que as questões sejam cada vez mais desafiadoras e progressivamente viáveis para alcançar os objetivos de uma aprendizagem eficiente, eficaz e produtiva. Almeja que o discente reconheça o conhecimento que já possui, identificando o que deve ser aprendido, adquirindoo e trabalhando para resolver a problemática. Torna o discente mais próximo ao docente, mais 
engajado, favorece a troca de informações, pensamentos e elucidação de seus interesses (NG et al., 20II).

O desenvolvimento da $\mathrm{ABP}$ foi baseado principalmente em dois métodos de instituições americanas: I) o método de casos de ensino da Escola de Direito em Harvard em 1920 (NG et al., $20 \mathrm{II}$ et al., 20II); e 2) o modelo de currículo baseado em sistemas para o ensino de medicina, desenvolvido em 1950 pela Case Western Reserve University em Clevaland (BOUD; FELETTI, 1999). Insatisfeitos com a formação geral dos cursos de medicina e baseado nesses dois métodos precedentes, em meados da década de 60, um grupo de 20 professores coordenados por John Evans da McMaster University, na cidade de Hamilton, província de Ontário, no Canadá, desenvolveu então - Aprendizado Baseado em Problemas (ABP) ou Problem-Base Learning (PBL) (MARTINS, 20I3).

A partir de então, esta metodologia foi adotada em diversas universidades do mundo na área médica como na Universidade de Limburg, em Maastricht (Holanda), na Universidade de Newcastle (Austrália), na Faculdade de Medicina de Hong Kong (China), na Escola de Saúde Pública do Ceará (Brasil), em Ciências Médicas da Universidade Estadual de Londrina (Brasil), na Faculdade de Medicina FAMEMA (Brasil). Também foi adotada em diferentes áreas do conhecimento como na Escola de Ciências, Artes e Humanidades da Universidade de São Paulo (Brasil), em cursos de arquitetura na Universidade de Newcastle (Austrália), de trabalho social na Universidade de New South Wales (Austrália), de terapia ocupacional na Brunel University College (Reino Unido), de fisioterapia na Universidade de McMaster (Canada), em ciências veterinárias na Universidade de Queensland (Austrália), em engenharia mecânica no Colégio Imperial de Ciência e Tecnologia (Reino Unido) (LEAL; MIRANDA; NOVA, 20I8).

Existe a separação da ABP de outras diferentes estratégias, caracterizadas por exibir uma circunstância de problema antes do esclarecimento das ideias que o solucionam. $\bigcirc$ êxito da metodologia se dá quando se coloca o aluno resolvendo problemas reais, tornando-se algo motivador e, consequentemente, o envolvimento ocorre de forma orgânica, natural. A ABP pode ser usada para viabilizar o desenvolvimento de uma rede conceitual, aumentando a possibilidade de retenção dos objetivos gerais $\mathrm{da}(\mathrm{s})$ disciplina(s) baseada(s) em problemas.

Um dos fundamentos da ABP é gerar no aluno a satisfação, o prazer pela busca do conhecimento através das ferramentas existentes, tornando-o responsável pelo seu processo de aprendizado. É basicamente um método de aprendizagem que usa problemas reais ou simulados para despertar, conscientizar e encorajar o discente a conhecer teorias, desenvolver competências e condutas.

Ao contrário dos problemas usados em métodos tradicionais, um problema da ABP é aberto, isto é, não tem uma única resposta correta, mas uma ou mais respostas adequadas, observando as 
restrições impostas pelo uso da própria situação problema e com o auxílio do contexto acadêmico em que está inserido. Em alguns casos, os problemas utilizados podem nem mesmo ter uma resposta certa ou errada. Ao invés desse tipo de resposta, o método se baseia em áreas cognitivas de estimulo ao aprendizado de ativação e reestruturação do conhecimento pregresso do estudante. Isso se dá através de discussões cooperadas sobre o problema, pela construção de uma rede semântica apropriada através da geração de um discurso interno e surgimento de curiosidade epistêmica devido à relevância do problema (GONZÁLEZ; BATANERO, 2016).

$A$ mera compleição de uma tarefa é menos relevante à metodologia $A B P$ do que 0 conhecimento, atitudes e habilidades construídas durante a busca da resolução do problema. Assumindo a responsabilidade na construção desse conhecimento, o aluno sai da posição de passividade de aprendizado e assume o compromisso com as suas próprias dúvidas e anseios, como um pesquisador. Assim, ao dirimir o problema, o aluno adota uma atitude altruísta, pois pode, além de solucionar ou amenizar o problema, seja ele industrial ou social, e desde que bem orientado e estruturado, pode auxiliar também na produção de conhecimento, não atuando apenas como repetidor do mesmo (CARVALHO et al., 2017).

Hoje, com o avanço da ciência e da tecnologia nota-se com uma maior nitidez a complexidade de algumas situações-problema e a necessidade da relação de vários conhecimentos para solucionálos. Quanto mais se estuda e se aprende, mais destacada é a nossa melhoria. A cada progressão, na totalidade dos exercícios realizados, inúmeras coisas diferentes começam a melhorar, já que se associa as informações de vários períodos do passado ao presente. Além do mais, fazendo novas associações, novos pensamentos começam a se formar e, assim, novas maneiras de agir começam a ser construídas. Esse cenário abre precedente para a inter e transdisciplinariedade, almejando a compreensão e resolução de problemas cada vez mais complexos.

Assim, é preciso cada vez mais aproximar os saberes de áreas distintas, colaborando com a troca de ideias e socialização do aprendizado. Em outras palavras, buscando o dinamismo do conhecimento, permitindo com que o aluno participe com a resolução dos problemas e contribua de maneira efetiva e fidedigna não só com a academia ao transferir sua sapiência, mas também com o desenvolvimento da sociedade.

\section{Metodologia de Problematização (MP) ou Inquiry-Based Learning (IBL)}

A Metodologia de Problematização (MP) oficialmente foi concebida em 1980 na Universidade do Havaí como uma sugestão metodológica que examinava uma questão de módulos educacionais orientados, caracterizando os estudos aprendidos e quais habilidades intelectuais e afetivas seriam adquiridas. Essa metodologia é baseada em circunstâncias em que os tópicos eram relacionados com a 
vida em sociedade, concernentes, portanto, a problemas sociais (FELETTI, 1993). Duas décadas antes do seu nascimento oficial, Paulo Freire, educador brasileiro, já defendia entusiasticamente fundamentos semelhantes ao desta metodologia, alicerçados em problemas sociais (RIOS, 2006).

Em sua maioria, os problemas relacionados com essa metodologia apresentam um caráter de ordem social, vinculados a educação, a saúde, a cultura, a relações sociais. A impressão de que a engenharia se distancia desses assuntos, por não se tratar de um curso voltado a área de humanas, pode induzir a ideia de que a metodologia não é adequada ao curso. Contudo, observa-se, quando analisada as competências do engenheiro, que ocorre exatamente o oposto, pois espera-se que esses profissionais desenvolvam soluções não só para problemas técnicos, mas também problemas sociais, atuais e futuros, tendo impacto direto nas pessoas, na sociedade e no meio ambiente.

Em alguns casos, por exemplo, dependendo do período no qual o futuro engenheiro se encontra no curso, ele já teve a oportunidade de se deparar com situações-problema fora da academia, que podem ser resolvidos e/ou amenizados com recursos assimilados em diferentes disciplinas. Nesse caso, o discente reconhece o problema, não necessitando do docente para apresentá-lo. Segundo Berbel (1998, p. 149), esse é o ponto divergente entre a Metodologia de Problematização (MP) e a ABP, ela relata que:

Na Metodologia da Problematização os problemas são identificados pelos alunos, pela observação da realidade, na qual as questões de estudo estão acontecendo. Observada de diferentes ângulos, a realidade manifesta-se para alunos e professores com suas características e contradições, nos fatos concretos e daí são extraídos os problemas. A realidade é problematizada pelos alunos.

Dessa forma, quando o discente se depara com o problema há um aumento do engajamento, o que, por sua vez, maximiza a probabilidade da efetividade do método, ao contrário do que acontece quando a situação é apresentada pelo docente. No entanto, para que isso ocorra, as etapas do processo devem ser bem conduzidas pelo professor, possibilitando uma boa abordagem crítico-reflexiva pelos alunos.

O plano apresentado por Bordenave e Pereira (1982), conhecido como Método do Arco de Charles Maguerez, é utilizado para retratar de forma progressiva as etapas utilizadas na Metodologia de Problematização. Os autores evidenciam cinco etapas para o desenvolvimento do Arco: Observação da Realidade; Pontos-Chave;Teorização; Hipóteses de Solução e Aplicação à Realidade (prática) (WALL; PERES, 20I2).

Quando se analisa as etapas relatadas no Arco de Maguerez, observa-se a semelhança de uma aprendizagem voltada a investigação, onde os alunos delimitam um problema, determinam um estado da arte, selecionam métodos, configuram um modelo, realizam experimentos, interpretam resultados a luz de métodos e teorias e, por fim, publicam seus resultados. Dessa forma, fomenta-se uma disposição 
de aprendizagem baseada na pesquisa, outorgando aos futuros engenheiros o desenvolvimento de sua capacidade de analisar e moldar o campo profissional através de seus conhecimentos teóricos, realizando suas atividades com uma disposição orientada para a pesquisa.

Os engenheiros, como já mencionado, devem ser criativos solucionadores e detectores de problemas. No entanto, criatividade e inovação não podem ser aprendidas por rotas de memorização, por isso o Arco de Maguerez constitui-se em um importante arquétipo para induzir essas habilidades nos estudantes. Assim, decisivas habilidades para a carreira, como trabalhar de forma independente, comunicar-se, organizar-se, podem ser desenvolvidas assumindo a responsabilidade por processos e produtos.

A MP ganhou maior significado no decorrer do Processo de Bolonha (BOLOGNA PROCESS, 1999). O Processo de Bolonha é uma sequência progressiva de reuniões e esclarecimentos entre nações europeias para garantir a unificação da educação avançada entre os países membros do continente diante das transformações da sociedade na virada do séc. XXI. Segundo Araújo e Durães (2018), a interpretação de suas diretrizes sugere possíveis impactos na educação superior brasileira, refletindo diretamente em mudanças no currículo em engenharia.

Baseado em recomendações do Conselho Científico Alemão, oriundo do processo de Bolonha, a MP aufere notoriedade, pois visa que o futuro engenheiro adquira a aptidão essencial de lidar com os problemas e tarefas típicas da prática profissional e o conhecimento disciplinar. O que leva à capacidade de definir soluções, em uma apuração acadêmica do assunto, inserindo competência reflexiva no campo profissional (CONSELHO ALEMÃO DE CIÊNCIA, 200I).

Além da versatilidade que a ferramenta apresenta, podendo ser aplicada em diferentes disciplinas dentro do escopo das engenharias, ela denota ainda a polivalência de utilização como método, que pode ser utilizado tanto para a graduação como para a pós-graduação, influenciando diretamente no aprendizado contínuo do discente desde a sua vida acadêmica à profissional.

\section{Aprendizagem Baseada em Equipes (ABE) ou Team-Based Learning (TBL)}

"Se eu vi mais longe, foi por estar de pé sobre ombros de gigantes". Essa metáfora foi traçada no século XII, atribuída a Bernardo de Chartres (BONNIE et al., 2016), mas ficou mais conhecida quando citada por Isaac Newton em sua carta para Hooke, em 1675 (NEWTON; HOOKE, 1675). Isaac Newton referia-se as descobertas de outros pensadores que o antecederam, como Descartes (1596-1650), Kepler (I57I-1630) e Galileu (1564-1642), fundamentais para seu trabalho. Através de sua frase, podemos concluir que sem estes cientistas o seu trabalho não teria êxito. Assim, podemos observar que há maior efetividade do trabalho quando realizado por várias pessoas do que quando 
feito por um único indivíduo, apesar desse sinergismo não ter acontecido ao mesmo tempo no caso de Newton.

Segundo alguns estudos, em $98 \%$ das vezes, a performance da equipe suplanta o desempenho do melhor membro do grupo separadamente (BOLLELA et al., 20I4; PARMELEE et al., 20I2). Dessa forma, com o trabalho em time é possível desenvolver mais facilmente competências exigidas do engenheiro do século $\mathrm{XXI}$, como a tomada de decisão e o trabalho colaborativo e efetivo em grupo.

A Aprendizagem Baseada em Equipes ( $A B E$ ) surgiu da investigação de uma estratégia que associa entendimentos sem $\circ$ uso de aulas expositivas, uma técnica frequentemente usada na abordagem da educação tradicional. Essa metodologia foi desenvolvida em uma escola de negócios, na década de 1990, nos Estados Unidos por um professor com o intuito de aproveitar as vantagens da aprendizagem de pequenos grupos em grandes times de alunos (SWEET; MICHAELSEN, 2007).

$A A B E$ é um sistema de aprendizado dinâmico que por meio de grupos, oferece uma condição construída de forma cooperativa, na qual a concorrência pode existir de vez em quando, mas sua atenção está voltada para a apreciação da criação agregada. $O$ objetivo é maximizar o interesse do aluno com aulas movimentadas, focadas na realidade e na aplicação dos conhecimentos adquiridos.

$A$ ABE é um método de instrução ativa e colaborativa, que é centrada no aluno e orientada por um instrutor. Os alunos são responsáveis pela sua própria preparação e envolvimento durante a aula, e são obrigados a aplicar seus conhecimentos na resolução de problemas autênticos que simulam situações da vida profissional.

Na educação convencional, normalmente a eficácia da transferência do conteúdo do professor especialista afeta diretamente os resultados do processo de aprendizado, ou seja, um ensino pouco eficaz leva a um desfecho insatisfatório. Já na $A B E$ o professor tem o papel de facilitador, sendo responsável pela gestão da sala de aula e não pela transmissão de conhecimento através de conteúdo. No entanto, o docente tem efeito direto e influencia substancialmente no aprendizado dos alunos.

Segundo Rotgans e colaboradores (2019), atualmente não está claro porque o facilitador tem um efeito positivo na aprendizagem dos alunos na $A B E$. É possível que no processo de gestão da classe, o facilitador represente comportamentos de apoio à aprendizagem e isso tenha um efeito direto na aprendizagem do aluno. Por exemplo, o facilitador frequentemente encoraja a prontidão dos alunos na elaboração e geração de perguntas durante os testes e também a resposta do aluno às perguntas de seus colegas, o que segundo os autores, explica a associação positiva do facilitador com a proatividade do aluno, mas não a relação com a aprendizagem.

O trabalho em grupo tem o potencial de suscitar a proatividade, bem como atitudes positivas do aluno em relação aos demais componentes, colocando-o como protagonista no processo de aprendizagem. No entanto, isso é relativo, pois depende, por exemplo, da idade do discente. Existe 
uma associação significativa entre idade e mudança na sua percepção do trabalho em equipe, onde alunos mais velhos tendem a preferir o estudo individual, enquanto os alunos mais jovens gostam de trabalho em grupo (GALLEGOS; PEETERS, 20I I).

Michaelsen e Sweet (2008) relatam que a aprendizagem em equipe permite o uso apropriado de recursos de ensino, sem renunciar a capacidade de desenvolver habilidades cognitivas de alto nível nos alunos, concedendo apoio social e propiciando o desenvolvimento de habilidades interpessoais e de grupo, além de construir e manter o entusiasmo dos membros do corpo docente. Dessa forma, com tal metodologia de aprendizado, o discente pode desenvolver aptidões como conduzir e projetar experimentos, sistemas, componentes ou processos. Outrossim, a metodologia permite ao discente identificar, resolver e até levantar problemas em sua área específica de engenharia com níveis mais elevados de confiança nas suas habilidades e também entender o impacto global dessas intervenções no contexto social.

O trabalho em equipe pode ser usado para aprimorar características, por exemplo, habilidades analíticas, engenhosidade prática, criatividade, comunicação, liderança, profissionalismo, dinamismo, agilidade, resiliência, princípios de negócios, gestão e ética. Além disso, auxilia no desenvolvimento do trabalho em grupos multidisciplinares e de uma comunicação mais efetiva, visto que os alunos têm que lidar com a pluralidade de ideias, tanto para transmiti-las de forma adequada quanto para aceitá-las. Assim, atitudes mais positivas sobre a qualidade de sua instrução, um maior senso de comunidade, e talvez um nível mais alto de empregabilidade resultante da experiência com $\circ$ trabalho em equipe, podem ser gerados.

Segundo Michaelsen e Sweet (2008), a ABE é uma ferramenta metodológica que se divide em 4 elementos, que são:

- Formação estratégica de equipes de 5 a 7 membros, garantindo assim recursos intelectuais suficientes;

- Designação individual pré-aula com, por exemplo, leituras seguidas por testes individuais e em equipe;

- Otimização de habilidades de pensamento crítico dos alunos usando atividades e tarefas cuidadosamente planejadas;

- Criação e administração de um sistema de avaliação e feedback por pares.

Os níveis de aprendizado dado pela Taxonomia de Bloom se assemelham a Pirâmide de Aprendizagem de Glasser, citada na seção de Metodologias Alternativas, e que, por sua vez, são instrumentos pedagógicos que estão de acordo com a chamada "estratégia 4S", criada por Michaelsen e Sweet (2008) e aplicadas na ABE, estratégia essa que vem de quatro expressões do inglês Significant Problem, Same Problem, Specific Choice e Simultaneous Reporting, que em uma tradução literal são 
Problema Significativo, Mesmo Problema, Escolha Específica e Relatórios Simultâneos, respectivamente. Estes são elementos essenciais para a aplicação da metodologia de aprendizagem de trabalho em equipe.

O Problema Significativo é um elemento estratégico, onde o exercício de aplicação deve ser suficientemente detalhado e complexo para motivar o aluno a gerar discussões prolíficas dentro das equipes. No elemento Mesmo Problema todas as equipes devem trabalhar exatamente no mesmo problema, permitindo às equipes confrontar suas respostas com as de outros grupos. Dessa forma a curiosidade das equipes é despertada, garantindo que os alunos prestem mais atenção e resultando em maior engajamento. Com relação ao elemento Escolha Especifica, os alunos aprendem a justificar, elaborar, defender e discutir a decisão escolhida. Isso ocorre através da realização de exercícios de aplicação, apresentados como perguntas de escolha específicas, como múltipla escolha, cálculo de um parâmetro, organização de itens, organização em categorias, etc. Por fim, os alunos tomam uma decisão colaborativa, dando uma resposta específica, simulando uma situação lida no ambiente profissional. $E$ no elemento de Relatórios Simultâneos as equipes devem relatar suas respostas, simultaneamente, para incentivar a capacidade de prestar contas e evitar resultados ao acaso. Um elemento que também é essencial na aprendizagem em equipe é a avaliação de pares, que tem por objetivo responsabilizar os indivíduos por suas equipes e diminuir a probabilidade de ociosidade social (MICHAELSEN; SWEET, 2008).

Assim, a $A B E$ é um método instrucional dividido em etapas individuais e em equipe, que coloca os alunos em papéis de maior autonomia e responsabilidade por seu aprendizado, desenvolvendo habilidades cooperativas altamente úteis no mercado de trabalho do engenheiro contemporâneo. Permite ainda, uma compreensão mais profunda dos conteúdos ministrados e prepara o aluno de maneira mais eficiente para avaliação e desempenho do curso.

\section{Comparação ABP, MP e ABE}

Para a comparação das metodologias ativas, entre elas e até mesmo com as aulas tradicionais em formato de palestra, é necessário equiparar os métodos de avaliação para se ter um quantitativo fidedigno dos resultados das metodologias de aprendizagem. A nota sempre foi o parâmetro de avaliação mais utilizado na educação tradicional e, ainda hoje, é quase que na sua totalidade motivo de comparação da eficiência das metodologias. Alguns países como Singapura, um dos líderes de educação mundial no Programa Internacional de Avaliação de Estudantes (WOOD, 2018), desde 2019 tem mudado isso ao eliminar progressivamente o ranking de notas para estimular o aprendizado e inibir a competitividade entre os alunos, através do ajuste das estruturas de avaliação escolar nos níveis 
primário e secundário. Contudo, a maioria dos países ainda utiliza o sistema numérico de avaliação e essa prática perpetua-se no ensino superior.

A avaliação é o ponto principal para quantificar a efetividade das metodologias de aprendizagem. No entanto, a avaliação tradicional, através de notas, é pautada na quantidade de conteúdos ministrados, preterindo algumas competências e, além disso, podendo causar efeitos prejudiciais na vida dos estudantes. Segundo Leite e Kager (2009), "as práticas tradicionais de avaliação escolar podem ter efeitos deletérios na relação que se estabelece entre os alunos e os objetos de conhecimento em questão" (LEITE; KAGER, 2009, p. 132).

Dessa forma, são necessárias avaliações díspares. Dentre elas, avaliações de aprendizagem que não sejam pautadas na quantidade de conteúdo, mas sim voltadas para a formação do discente como cidadão, com a valorização de atitudes críticas, bem como na preocupação com a qualidade do ensino. Que levem também em consideração as competências necessárias para o futuro engenheiro, mas que vão além do desenvolvimento profissional. Somente dessa forma poderemos comparar as metodologias de aprendizagem em um nível igualitário.

Como o presente trabalho não é empírico, uma comparação qualitativa entre as metodologias ativas não é objetivada nessa seção. Assim, apontar quais são as principais diferenças e semelhanças entre os métodos, com o intuito de esclarecer muitas controvérsias sobre suas aplicações na instrução das metodologias ativas, é o objetivo aqui pretendido, de modo que possa servir de reflexão aos profissionais de educação superior.

Ao analisar as estratégias de Metodologia de Problematização (MP) e de Aprendizado Baseado em Problemas ( $A B P)$ podemos observar que, embora elas pareçam abordagens pedagogicamente equivalentes, existem algumas diferenças devido a discrepância das técnicas relacionadas ao treinamento, resultado e campo apropriado de utilização. Nesse sentido, a orientação e a abordagem de toda estratégia requerem um olhar apropriado.

Enquanto a MP está fundamentada em pesquisa através da aquisição de informações de percepções diretas, utilizando apurações dedutivas por meio de problemas mal estruturados, a ABP depende de impulsionar o aprendizado através da investigação, explicação e resolução, partindo de problemas reais e significativos. Portanto, a ABP pode ser vista como o ofício do pensamento crítico e a MP a especialidade de abordar ou levantar questões sobre um tema.

O princípio da MP é adquirir conhecimento a partir de observações diretas, usando perguntas dedutivas, e da $A B P$ é de maximizar o aprendizado com investigação, explicação e resolução, partindo de problemas reais e significativos. Dessa forma, a nosso ver, a ABP se enquadra melhor nas situações de estudos de casos que ocorrem em processos da engenharia, por apresentar melhores resultados 
de aprendizado para solução de problemas. Já a MP apresenta uma melhor abordagem de aprendizado para a natureza humana.

$\mathrm{Na} A B P$, informações e habilidades anteriores são importantes para a prova reconhecível de questões, explicitação de códigos e elaboração de aprendizado. Não que isso não tenha influência na MP, sucede-se que nessa técnica há um pré-requisito mais notável nas ideias de investigação, criação e aplicação, podendo o aluno produzir conhecimento a partir de sua percepção.

Em ambos os métodos o professor tem um papel de líder e facilitador, usando um termo difundido na atualidade no Brasil. Na MP, o professor deve ser um guia, fonte das perguntas de condução. Já na $A B P$, é o aluno que deve ser a fonte das perguntas de condução, determinando se existe um problema, criando uma declaração exata do mesmo, identificando informações, dados e objetivos de aprendizado e, por fim, criando um plano de trabalho. Na MP, por sua vez, o papel do estudante é interpretar e explicar, levantando a hipótese de projetar e direcionar tarefas próprias, além de compartilhar autoridade para obter respostas.

A metodologia $A B P$, de fato, parece ser a mais indicada a cursos de engenharia do que a MP, pelo desenvolvimento de habilidades eficazes de resolução de problemas, habilidades autodirigidas, aprendizado duradouro e esforços conjuntos conectados. Contudo, alguns resultados específicos da MP podem complementar o ABP na melhoria de questões sociais e pessoais, algo significativo na carreira do engenheiro.

Assim como a $\mathrm{ABP}$ auxilia na formulação e resolução de problemas na engenharia, a Aprendizagem Baseada em Equipes ( $\mathrm{ABE}$ ) também tem papel fundamental na geração dessas competências, bem como no entendimento do impacto das soluções desses problemas em um contexto global e social. Tanto a $A B P$ quanto a $A B E$ têm por princípio usar problemas profissionais como alicerce metodológico e aprendizado em pequenos grupos, se encaixando perfeitamente com os princípios atuais de projeto instrucional dos cursos de engenharia.

Outra característica de instrução em comum entre a $A B P$ e a $A B E$ é a de que os alunos são encorajados durante o trabalho em grupo a aplicar seus novos conhecimentos nos problemas, além de integrá-los ou transferi-los, relatando-os aos colegas com suas próprias palavras. No entanto, na ABP nenhuma tarefa de leitura prévia é exigida para a aula, antes da discussão em grupo, portanto, a exposição a novos conhecimentos somente ocorre após a discussão inicial em grupo, enquanto que no $A B E$ a exposição a novos conteúdos acontece antes da discussão em equipe, na realização da tarefa anterior as aulas. Por isso, os alunos são testados individualmente e também em equipe, para verificar sua compreensão das tarefas de leitura e conhecimento prévio.

A autonomia dos alunos na decisão de significância dos conteúdos é maior na $A B P$ do que na $A B E$, pois os alunos geram problemas para o auto estudo, ou seja, apontam as questões controversas 
depois de uma discussão inicial em grupo, auxiliando o professor na triagem dos problemas profissionalmente relevantes. Já na $A B E$, o professor é quem define o assunto para o estudo em sala de aula, com base no conteúdo programático da disciplina ou através das questões que ainda não estão bem elucidadas.

$\mathrm{Na}$ metodologia $\mathrm{ABP}$ um número limitado de palestras complementares deve ser realizado pelo professor, normalmente após o auto estudo, seguidas de uma discussão final do grupo. Na $A B E$, por sua vez, o papel do professor é de natureza corretiva ou confirmatória, agindo como um instrutor após a exposição inicial dos alunos ao conteúdo, através de tarefas de estudo pré-aula. Nesta metodologia, o professor atua como um intermediador em dois momentos em classe, na conclusão da equipe, após os testes realizados, e ao fim da sessão plenária de discussões, nas quais as equipes desafiam as respostas de outros grupos, algo que não acontece na $A B P$. Consequentemente, não há aulas expositivas tradicionais na $A B E$.

$\mathrm{Na} A B E$, os membros da equipe avaliam-se entre si acerca de suas contribuições para o sucesso do grupo e para o seu próprio aprendizado. Essas críticas dos colegas influenciam de forma efetiva nas contribuições dos alunos para a equipe e no compromisso com o trabalho em grupo. Essas competências são importantes no mercado de trabalho, pois aumentam a consciência dos comportamentos desejados no grupo, a interdependência social positiva, a motivação intrínseca, o apoio mútuo e a colaboração entre os membros dos grupos. Já na ABP esse tipo de avaliação entre pares não ocorre.

Dessa forma, quando se analisa a $A B P$ e $A B E$, observam-se pontos fortes nas duas metodologias e que, em alguns casos, são complementares. $A$ avaliação por pares, técnica típica da $A B E$, por exemplo, poderia ser utilizada na $A B P$. A geração de problemas de aprendizagem pelos alunos da ABP, bem como as discussões em grupo antes das tarefas de pré-leitura, poderia ser usada na $A B E$, agregando assim mais qualidade em ambas as metodologias.

Todas as metodologias tratadas compartilham importantes semelhanças ao abordarem problemas em diferentes formas, sendo algumas mais ou menos propícias para aplicação na engenharia. No entanto, todas essas metodologias compartilham preceitos essenciais na formação de importantes competências à vida profissional, desde que bem conduzidas. Ao combinar as qualidades das diferentes metodologias, pode-se otimizar o aprendizado dos alunos através dessas técnicas ativas e tornar mais eficiente a transmissão do conhecimento pelos docentes.

\section{Considerações finais}

A importância de uma metodologia de ensino condizente a uma sociedade de informação e de incessante transição como a nossa é incontestável. Fica clara a necessidade da geração de habilidades 
e competências aos profissionais engenheiros do sec. XXI, que thes permitam se adaptar a essas constates mudanças. No entanto, isso é pouco observado na maioria dos cursos de engenharia no Brasil, pois a academia ainda não dá a devida notoriedade ao ensino se comparado à pesquisa. Nesse contexto, instituições estrangeiras renomadas de educação despontam, pois atribuem mais relevância ao ensino. Diante disso, podem servir de exemplo na equalização da balança pesquisa/ensino e, assim, permitir que os cursos e profissionais ganhem cada vez mais qualidade. Países como os EUA conferem grau de Engenharia de Educação e possuem programas stricto sensu que pesquisam a melhor forma de aprendizado dos discentes, otimizando a maneira como os engenheiros são educados (BENSON et al., 2010).

O sinergismo de cursos de diferentes áreas é o que fortalece esses departamentos, levando a propostas e ações altamente criativas. Dessa forma, a interdisciplinaridade proporciona diferentes formas de pensar e agir, que trabalhando juntas resultam em inúmeras perspectivas, formas de pesquisa e bases de conhecimento. Isso influencia diretamente na formação de mestres e doutores qualificados a ensinar de maneira ativa e alternativa.

No Brasil, infelizmente, o cenário é bem diferente. Aqui há uma dependência quase que exclusiva da inquietação do professor para buscar metodologias de ensino alternativas e incorporá-las em suas aulas. Contudo, não basta apenas boa vontade, além da ciência das metodologias e o objetivo de competências a serem geradas, é necessário um exímio conhecimento da turma onde serão aplicadas. Cada turma apresenta características diferentes e, portanto, apresentarão melhores resultados com uma ou outra forma de aprendizagem. Isso permite a aplicação do método mais adequado ou uma hibridização que gere melhores resultados. Por isso, há a necessidade de propagar a importância de o educador elaborar um arcabouço instrutivo de várias metodologias ativas. A partir do instante em que se tem um cardápio de possibilidades, o docente pode escolher o que se adequa melhor ao seu contexto, tornando, então, a sala de aula o seu laboratório de ensino. Assim, a busca da melhoria do aprendizado em sala deve ser constante.

\section{Referências}

ABREU, M. C.; MASETTO, M. T. O professor universitário em aula. São Paulo; MG Editores, 1990.

AKERA, A. Bringing radical behaviorism to revolutionary Brazil and back: Fred Keller's Personalized System of Instruction and Cold War engineering education. J Hist Behav Sci.; I-19, 2017.

ARAÚJO, C. V. B.; SILVA, V. N.; DURÃES, S. J. The Bologna Process and curricular changes at higher education: What are skills for? Educacao e Pesquisa, 44, I-17, 2018. 
BARH, D.; BLUM, K.; MADIGAN M. A. OMICS: Biomedical Perspectives and Applications. CRC Press, Taylor \& Francis Group United States of America- 622 p, 2016.

BENSON, L. C.; BECKER, K.; COOPER, M. M.; GRIFFIN, O. H.; SMITH, K. A. Engineering education: Departments, degrees and directions. International Journal of Engineering Education, 26(5), 1042-1048, 2010.

BERBEL, N. N., Problematization and Problem-Based Learning: different words or different ways? Interface - Comunicação, Saúde, Educação, v.2, n.2, 1998.

BOLLELA, V. R., SENGER, M. H., TOURINHO, F. S. V., AMARAL E. Aprendizagem baseada em equipes: da teoria à prática. Tópicos Fundamentais Para $A$ Formação e $O$ Desenvolvimento Docente Para Professores dos Cursos da área da Saúde, Ribeirão Preto, v. 3, n. 47, p.293-300, 2014.

BOLOGNA PROCESS. European Higher Education Area, Disponível em: http://www.ehea.info/index.php, 1999, Acesso em 24 de março de 2020.

BONNIE, K.; VITASEK K, MANRODT K.; KLING J. Strategic Sourcing in the New Economy: Harnessing the Potential of Sourcing Business Models for Modern Procurement. Palgrave Macmillan. London United Kingdom. ISBN 978I I 37552204. 448 p, 2016.

BORDENAVE, J.; PEREIRA, A. Estratégias de ensino aprendizagem. 4. ed., Petrópolis: Vozes, 1982.

BOUD, D.; FELETI, G. The challenge of problem-based learning. Londres: Kogan, 1999.

CARVALHO, A. D. S.; OLIVEIRA, V. I.; GUEDES, A. C. B. S.; MARTINS J. L. Gestão da aprendizagem, proatividade e autonomia dos discentes: novas práticas. Aturá Revista PanAmazônica de Comunicação, Vol. I, n. 3, 2017.

CATALANI, C.; VELASCO, D. L. A maiêutica Socrática e o professo lipmaniano: uma relação possível? Revista Sul-Americana de Filosofia e Educação - RESAFE, 2-23, 2014.

CHIESA, M. Behaviorismo Radical: a filosofia e a ciência. Ed Celeiro IBAC Editora -Brasília DF, 2006.

CNI. Confederação Nacional da Indústria, Serviço Social da Indústria, Serviço Nacional de Aprendizagem Industrial, Instituto Euvaldo Lodi - Brasília Destaque de inovação: recomendações para o fortalecimento e modernização do ensino de Engenharia no Brasil. Disponível em: https://www.portaldaindustria.com.br/publicacoes/20 I8/3/destaques-de-inovacao-recomendacoespara-o-fortalecimento-e-modernizacao-do-ensino-de-engenharia-no-brasil/ 2018, Acesso em $06 \mathrm{de}$ jun. de 2020.

COHEN, R.; NEWTON-JOHNA, T.; SLATER, A. The relationship between Facebook and Instagram appearance-focused activities and body image concerns in young women. Body Image 23 183-187, 2017.

CONSELHO ALEMÃO DE CIÊNCIA. Empfehlungen zur künftigen Struktur der

Lehrerbildung. Disponível em: https://www.wissenschaftsrat.de/download/archiv/5065-0I.html, 200I, Acesso em 25 de ab. de 2020. 
CORNILLE, C. Humildade e diálogo. Numen: revista de estudos e pesquisa da religião, v. 10 , n. I e 2, p. 4I-59, 2007.

COSTA, E. R.; OLIVEIRA, K. E. A sexualidade segundo a teoria paicanalítica Freudiana e o papel dos pais neste contexto. Itinerarios Reflectiones, Volume 2. n II, 20 II.

DEMO, P. Educar pela Pesquisa. 4. ed. Campinas: Associados, 2000.

DEWEY, J. My pedagogic creed. The School Journal, Volume 54, Number 3 (January 16, 1897), pages 77-80, 1897.

FELETTI, G. Inquiry Based and Problem Based Learning: How Similar are these Approaches to Nursing and Medical Education? Higher Education Research \& Development, I2(2), 143-156, 1993.

FELDER, R. M. Matters of Style, ASEE Prism, 6(4), 18-23, 1996.

GALLEGOS, P.J.; PEETERS, J. M. A measure of teamwork perceptions for team-based learning. Currents in Pharmacy Teaching \& Learning. 3:30-35, 2011.

GONZÁLEZ, R.; BATANERO, F. A review of Problem-Based Learning applied to Engineering. EduRe Journal International Journal on Advancesin Education Research EduRe Journal No, 3(I), 2340-2504, 2016.

HORTON, B. 'I hear and I forget, I see and I remember, I do and I understand' - putting learning models into practice. Planet, 3(I), I2-I4, $200 \mathrm{I}$.

LEAL, E. A.; MIRANDA G. J.; NOVA S. P. C. C. Revolucionando a sala de aula: como envolver o estudante aplicando as técnicas de metodologias ativas de aprendizagem. Edit. Atlas São Paulo, 2018.

LEITE, S. A.; KAGER, S. Efeitos aversivos das práticas de avaliação da aprendizagem escolar. Ensaio, I7(62), I09-134, 2009.

MARTINS, D. B. Avaliação de habilidades e de atitudes em abordagem de problem-based learning no ensino de controle gerencial. Curitiba/PR. Dissertação (Mestrado em Ciências Contábeis) - Universidade Federal do Paraná - Brasil, 2013.

MAYER, V. F., Aplicações do Método caso em Sala de Aula. Rio de Janeiro: Fundação Getúlio Vargas, 2012.

MICHAELSEN, L.K; SWEET, M. The essential elements ofteam-based learning. New Dir. Teach. Learn., II6, I-99, 2008.

NEWTON, l.; HOOKE, R. Isaac Newton letter to Robert Hooke. Correspondência. February 5, 1675 Collection: Simon Gratz collection, Disponível em https://discover.hsp.org/Record/dc9792/Description\#tabnav, 1675, Acesso em 03 de ab. de 2020

NG, B. L. L.; YAP, K. C.; HOH, Y. K. Students' Perception of Interdisciplinary, Problem-Based Learning in a Food Biotechnology Course. Journal of Food Science Education, I (I), 4-8, $20 \mathrm{I}$ I. 
NIETZSCHE, F. Vontade de Potência. Ed. Vozes, ed. I, 528p, 20 II.

PARMELEE, D.; MICHAELSEN, L. K.; COOK, S.; HUDES, P. D. Team-based learning: A practical guide: AMEE Guide No. 65. Medical Teacher, 34(5), e275-e287, 2012.

PAULA, M. F. Alegria e Felicidade A experiência do processo liberador em Espinosa. Tese de doutorado Depto. De Filosofia da Faculdade de Filosofia, Letras e Ciências Humanas (FFLCH) da Universidade de São Paulo (USP) - Brasil, 2009.

PRZYBYLSKI, A. K.; MURAYAMA, K.; DEHAAN, C. R.; GLADWELL, V. Motivational, emotional, and behavioral correlates of fear of missing out. Computers in Human Behavior, 29(4), I84I-I848, 2013.

RIBEIRO, L. R.; MIZUKAM, I M. da G.N. A PBL na Universidade de Newcastle: Um Modelo para o Ensino de Engenharia no Brasil? Olhar de professor, 7(I): 133-147, 2004.

RIOS, N. H. A. Implementação do Arco de Maguerez como alternativa metodológica para validação da teoria da Problematização de Paulo Freire. In: 58 $^{a}$ Reunião Anual da SBPC, Florianópolis, 2006.

ROTGANS, J. I,; RAJALINGAM, P.; FERENCZI, M. A.; Low-Beeretal, N. A students' model of teambased learning. Health Professions Education, V 5, 4, p. 294-302, 2019.

SANTOS, C. M. R. G.; FERRARI, M. A. Aprendizagem ativa: contextos e experiências em comunicação. ISBN: 978- 85- 99679-78-4 (e-book). Disponível em:

https://www.faac.unesp.br/Home/Utilidades/aprendizagem-ativa---versao-digital.pdf, 2017, Acesso em 12 de jan. De 2020.

SHMIDT, H. G. Problem-based learning: rationale and description. Medical Education Limburg, v. 17 n. II-I6, 1983.

SILVA, F. L.; MUZARDO, F. T. Pirâmides e cones de aprendizagem: da abstração à hierarquização de estratégias de aprendizagem. Dialogia, 29, 169-179, 2018.

SOUSA, J. L.; SÁ RAMALHO, R. A. Um estudo das contribuições de Schopenhauer para a Ciência da Informação: o mundo como vontade e representação. Informação \& Informação, 24(I), I3I, 2019.

SWEET, M.; MICHAELSEN, L. K. How group dynamics research can inform the theory and practice of postsecondary small group learning. Educational Psychology Review, I9(I), 3I-47, 2007.

TOSEY, P.; MATHISON, J. Neuro-linguistic programming and learning theory: A response. Curriculum Journal, I4(3), 37I-388, 2003.

TSOU, J. Y. Genetic Epistemology and Piaget's Philosophy of Science: Piaget vs. Kuhn on Scientific Progress. Theory e Psychology, I6(2), 203-224, 2006.

VIANNA, D. M., CARVALHO, A. M. P. Formação permanente: a necessidade da interação entre a Ciência dos cientistas e a Ciência da sala de aula. Ciênc. educ. (Bauru) vol.6 no.l, 2000.

WALL, M. L.; PERES, A. M. The problematization method applied to the subject nursing administration. Invest Educ Enferm, 30(I), 269-276, 2012. 
WOOD, J. Children in Singapore will no longer be ranked by exam results. Here's why. Disponível em: https://www.weforum.org/agenda/20 I8//0/singapore-has-abolished-school-exam-rankings-here-swhyl, 2018, Acesso em 25 de fevereiro de 2020.

YANI, A., ADIANSYAH, R. Developing Problem-Based Learning Module For Biotechnology Concepts. Journal Pendidikan Sains, 5(2), 46-56, 2017.

Recebido em: 22 de julho de 2020.

Versão corrigida recebida em: 16 de abril de 2021.

Aceito em: 04 de maio de 2021 .

Publicado online em: 04 de fevereiro de 2022. 